\title{
CD24 is a Potential Biomarker for Prognosis in Human Breast Carcinoma
}

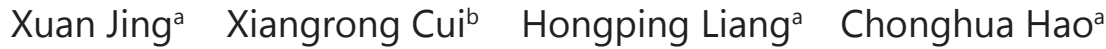 \\ Zhining Yang ${ }^{a}$ Xiaogai Li ${ }^{e} \quad$ Xiaojuan Yang ${ }^{d}$ Chongyang Han ${ }^{c}$
}

aDepartment of Clinical laboratory, Shanxi Provincial People's Hospital, Affiliate of Shanxi Medical University, Taiyuan, ${ }^{b}$ Reproductive Medicine Center, Children's Hospital of Shanxi and Women Health Center of Shanxi, Affiliate of Shanxi Medical University, Taiyuan, 'Department of Nephrology, Shanxi Provincial People's Hospital, Affiliate of Shanxi Medical University, Taiyuan, 'Department of Respiration, Shanxi Provincial People's Hospital, Affiliate of Shanxi Medical University, Taiyuan, eDepartment of Clinical Laboratory, The First Affiliated Hospital of Zhengzhou University, Key Laboratory of Laboratory Medicine of Henan, Zhengzhou, China

\section{Key Words}

Cd24 • Breast carcinoma • Prognosis • Transcription

\begin{abstract}
Background/Aims: CD24 is a highly glycosylated mucin-like antigen on the cell surface, which has recently emerged as a novel oncogene and metastasis promoter. We performed bioinformatics analysis to investigate whether CD24 can serve as a prognostic indicator in breast cancer. Methods: CD24 expression was assessed using SAGE Genie tools and Oncomine analysis. The PrognoScan database, Kaplan-Meier Plotter, and bc-GenExMiner were used to identify the prognostic roles of CD24 in breast cancer. Results: We found that CD24 was more frequently overexpressed in breast cancer than in normal breast tissue and correlated with worse prognosis. Meanwhile, high CD24 expression was associated with increased risk of HER2, basal-like, triple-negative breast cancer, and higher Scarff-Bloom-Richardson grade. Data mining in multiple big databases confirmed a positive correlation between CD24 mRNA expression and SDC1 mRNA expression in breast cancer tissue. Conclusions: Our findings suggest that CD24 overexpression is more common in breast cancer than in corresponding normal tissue. In addition, CD24 and SDC1 can serve as prognostic indicators for breast cancer. However, large-scale and comprehensive research is needed to further confirm these results.

(C) 2018 The Author(s)

Published by S. Karger AG, Basel
\end{abstract}

\section{Introduction}

Breast cancer is one of the most frequently diagnosed malignancies and is a leading cause of cancer-related death among women worldwide [1-3]. Despite advances in early clinical diagnosis and treatment strategies, the prognosis of breast cancer remains poor $X$. Jing, X. Cui and $\mathrm{H}$. Liang contributed equally to this work. 
Jing et al.: CD24 is a Potential Biomarker in Human Breast Carcinoma

[4-6]. Therefore, identifying sensitive and specific biomarkers for prognosis is urgently required.

Cluster of differentiation (CD) 24 is a small glycosyl phosphatidylinositol (GPI)-linked membrane glycoprotein (27-30 amino acids in length) with glycosylation sites that bind P-selectin [7, 8]. High expression levels of CD24 have been identified in various types of cancers - such as breast, prostate, pancreas, ovary, colorectal, and bladder cancers-and indicate poor prognosis [9-12]. CD24 has also been demonstrated to promote tumor cell proliferation, invasion, and metastasis in many types of cancers [3, 13, 14]. Also targeting CD24 for treatment of colorectal and pancreatic cancer using monoclonal antibodies or small interfering RNA reduce the tumor burden in tumor bearing mice [15]. Moreover, tumorigenesis and metastasis were reduced in CD24 knockout mice exposed to chemical carcinogens. Together, these findings indicate that CD24 may act not only as a potential therapeutic target, but also as a novel prognostic biomarker in cancer. In contrast, several studies revealed that absence or low expression of CD24 might be associated with tumor proliferation, invasiveness, or metastasis in breast cancer [16, 17].

Thus, in this study, we evaluated the significance of CD24 mRNA expression in human breast cancer by using The Cancer Genome Atlas (TCGA) data portal. The present study was performed to determine the expression pattern, potential function, and distinct prognostic value of CD24 in breast cancer by pooling all currently available data.

\section{Materials and Methods}

\section{SAGE analysis for CD24 expression}

All available published SAGE data on normal and malignant human tissues were assessed for CD24 gene expression [37-39]. The CD24 gene expression profiles were visually displayed using SAGE Genie tools (http://www.ncbi.nlm.nih.gov/SAGE/).

\section{Oncomine database analysis}

Oncomine database (https://www. oncomine.org/resource/login.html), an online tumor microarray database, was used to determine the transcription levels of CD24 in breast cancer. The expression fold change of CD24 in clinical cancer specimens compared to normal controls was obtained as the parameters of $p$-value $<1 \mathrm{E}$-4, fold change $>2$, and gene ranking in the top $10 \%$. The co-expression profile of the $C D 24$ gene in breast cancer was assessed and displayed as a heat map.

\section{Prognoscan database analysis}

The correlation between overall survival (OS) and CD24 mRNA expression was assessed using an online database, PrognoScan database (http://www.abren.net/PrognoScan/). This database is a powerful platform for evaluating potential tumor markers and therapeutic targets. To evaluate the OS of patients with breast cancer, patient samples were divided into two groups by median expression (high vs. low expression) and analyzed using PrognoScan. HR with 95\% confidence intervals (CI) and cox $p$-values were also computed. A p-value $<0.05$ was considered statistically significant.

\section{Kaplan-Meier plotter analysis}

Kaplan-Meier Plotter (http://kmplot.com/analysis/) is an online database of published microarray datasets that assess the effect of 54, 675 genes on survival using 10, 461 cancer samples (5, 143 breast, 1, 816 ovarian, 2, 437 lung, and 1, 065 gastric cancer). We used the Kaplan-Meier plotter to assess the correlation between RFS and CD24 mRNA expression in patients with breast cancer. The hazard ratio (HR) with $95 \%$ confidence intervals (CI) and log rank p-value were also computed.

\section{Breast Cancer Gene-Expression Miner v4.0 and UCSC Xena}

We used Breast Cancer Gene-Expression Miner v4.0 (bc-GenExMiner v4.0)-a statistical mining tool of published annotated genomic data including 36 annotated genomic datasets and 5861 breast cancer patients $[40,41]$ - to evaluate the expression of CD24 mRNA in breast cancer, as well as its association 
with prognosis. We also used the correlation module to assess the correlation between genes or identified clusters of correlated co-expressed genes located in the same chromosomal region. The heat map and the correlation between CD24 and co-expressed genes in the same patient cohort were further verified and analyzed using UCSC Xena (http://xena.ucsc.edu/).

\section{Results}

\section{CD24 transcript expression in breast cancer}

Because CD24 is a GPI-anchored cell surface protein, its expression profile was determined by performing SAGE Digital Gene Expression. Our analysis revealed that expression levels of CD24 were higher in brain, retina, thyroid, lung, breast, pancreas, and skin cancer tissues, compared with their corresponding normal tissues (Fig. 1). Oncomine analysis of cancer vs. normal tissue revealed that CD24 mRNA was significantly over-expressed in male breast carcinoma, medullary breast carcinoma, invasive ductal breast carcinoma, and invasive breast carcinoma (Table 1 , Fig. 2).

Genetic alterations of CD24 and clinicopathological parameters in breast cancer patients

As shown in Table 2, we performed Welch's test, using bcGenExMiner, to compare the transcription levels of CD24 among groups of patients, according to different clinicopathological characteristics. Our results demonstrated that there was no significant difference between the $\leq 51$ years old and $>51$ years old groups. Breast cancer patients with positive nodal status showed higher CD24 mRNA levels than those with negative nodal status. Estrogen receptor (ER) and progesterone receptor (PR)

Table 1. CD24 expression in breast cancer

\begin{tabular}{llllll}
\hline Cancer subtype & $p$-value & Fold change & $t$-test & Rank (\%) & Sample \\
\hline Male Breast Carcinoma & $5.13 \mathrm{E}-5$ & 3.091 & 7.036 & 1 & 1,602 \\
Medullary Breast Carcinoma & $5.12 \mathrm{E}-7$ & 2.461 & 5.374 & 11 & 176 \\
Invasive Ductal Breast Carcinoma & $1.64 \mathrm{E}-18$ & 2.024 & 9.649 & 24 & 2,316 \\
Invasive Breast Carcinoma & $9.78 \mathrm{E}-6$ & 2.430 & 4.907 & 33 & 59 \\
\hline
\end{tabular}

Fig. 2. CD24 analysis in breast cancer (Oncomine database). The box plot comparing specific CD24 expression in normal (left plot) and cancer tissue (right plot) was derived from Oncomine database. The analysis was shown in male breast carcinoma, medullary breast carcinoma, invasive ductal breast carcinoma, and invasive breast carcinoma relative to normal breast.

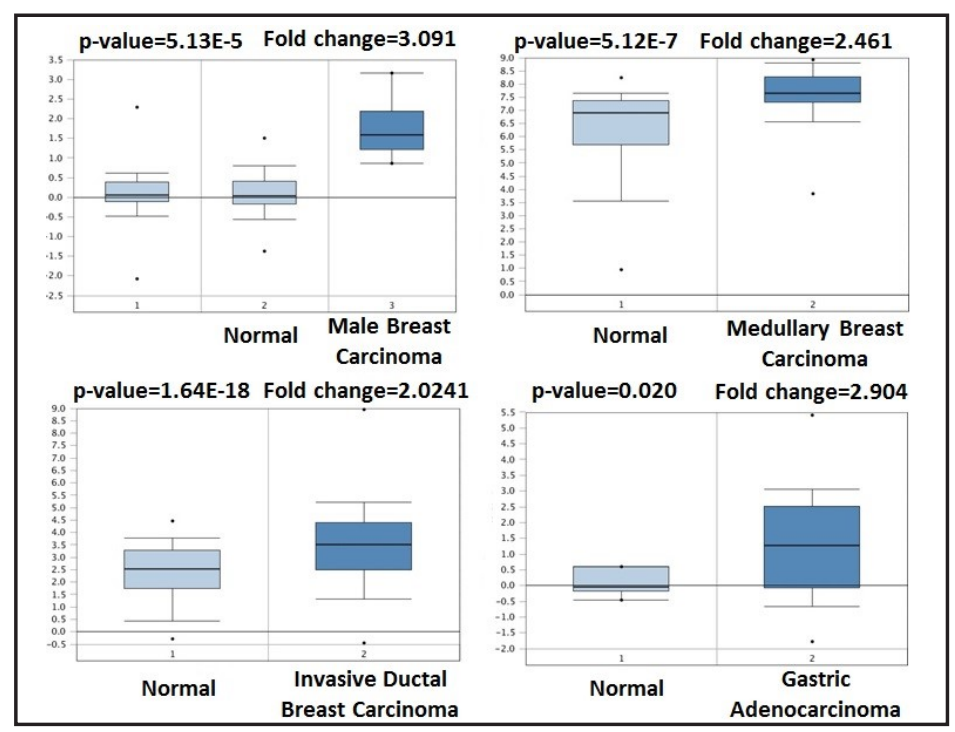

Fig. 1. Expression profile for CD24 in human breast cancer performed by the SAGE DGED. 
status were confirmed to correlate negatively with CD24 expression. Conversely, CD24 mRNA levels were higher in patients with human epidermal growth factor receptor 2 (HER2) positive tumors than in those with HER2-negative tumors (Table 2, Fig. 3). Between-group comparison also demonstrated significantly higher CD24 mRNA expression in cancers of the basal-like subtype than other subtypes and in triple-negative breast cancer (TNBC) than in non-TNBC (Table 2, Fig. 3). Among tumors with different ScarffBloom-Richardson (SBR) grades (Fig. 3), there was a global significant difference in CD24 expression, but the difference was not significant when individual groups were compared (SBR1 vs. SBR2, SBR1 vs. SBR3, and SBR2 vs. SBR3, $p>0.05$ ).

Association of CD24 expression and prognosis in breast cancer patients

PrognoScan database analysis showed that overexpression of CD24 correlated with low overall survival rates in patients with breast cancer $(\mathrm{HR}=1.18$, 95\% CI 1.08-1.30, $p=0.000226$ ) (Fig. 4). KaplanMeier analysis revealed that high levels of CD24 mRNA correlated with a shorter relapse-free survival (RFS) (Fig. 5). By performing data mining in bc-GenExMiner, we pooled previously available annotated genomic data to analyze the relationship between CD24 expression and metastatic relapse-free survival (MRFS). High levels of CD24 expression were associated with a higher risk

Table 2. The relationship between mRNA expression of CD24 and clinicopathological parameters of breast carcinoma

\begin{tabular}{|c|c|c|c|}
\hline Variables & No.* & mRNA & $p$-value \\
\hline \multicolumn{4}{|l|}{ Age } \\
\hline$\leq 51$ & 1392 & - & 0.0598 \\
\hline$>51$ & 2210 & - & \\
\hline \multicolumn{4}{|c|}{ Nodal status } \\
\hline- & 2493 & - & 0.0107 \\
\hline+ & 1562 & $\uparrow$ & \\
\hline \multicolumn{4}{|l|}{ ER (IHC) } \\
\hline- & 1446 & - & $<0.0001$ \\
\hline+ & 3766 & $\downarrow$ & \\
\hline \multicolumn{4}{|l|}{ PR (IHC) } \\
\hline- & 804 & - & $<0.0001$ \\
\hline+ & 1249 & $\downarrow$ & \\
\hline \multicolumn{4}{|c|}{ HER2 (IHC) } \\
\hline- & 1409 & - & $<0.0001$ \\
\hline+ & 201 & $\uparrow$ & \\
\hline \multicolumn{4}{|c|}{ Triple-negative Status } \\
\hline Not & 3922 & - & $<0.0001$ \\
\hline TNBC & 374 & $\uparrow$ & \\
\hline \multicolumn{4}{|c|}{ Basal-like Status } \\
\hline Not & 528 & - & $<0.0001$ \\
\hline Base-like & 580 & $\uparrow$ & \\
\hline
\end{tabular}

Fig. 3. The relationship between mRNA expression of CD24 and clinicopathological parameters in breast cancer patients. Global signifcant different between groups was assessed by Welch's test to generate $\mathrm{p}$ value, along with Dunnett-Tukey-Kramer's.

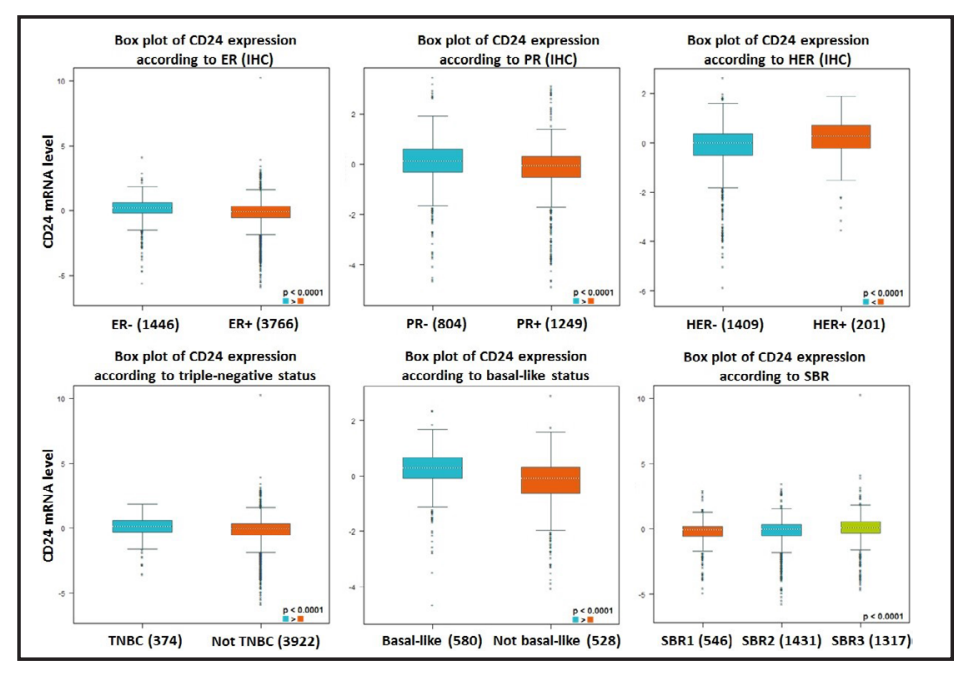

Fig. 4. The relationship between mRNA expression of CD24 and overall survival in breast cancer patients (PrognoScan database). The analysis of survival curve was identified as the threshold of cox p-value $<0.05$.

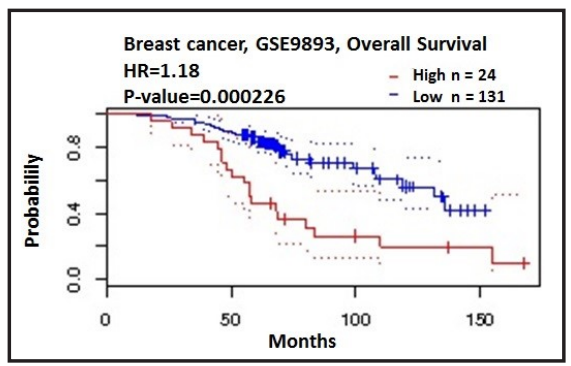


Fig. 5. The prognostic value of mRNA level of CD24 in breast cancer patients (RFS in Kaplan-Meier plotter).


Fig. 6. The relationship between CD24 expression and prognosis metastatic relapse-free survival (MRFS) in breast cancer (bc-GenExMiner v4.0). A: Forest plots displaying univariate Cox's analysis of CD24 expression and the risk of metastatic relapse (MR); B: Kaplan-Meier survival analysis showing the relationship between CD24 expression and MR-free survival.

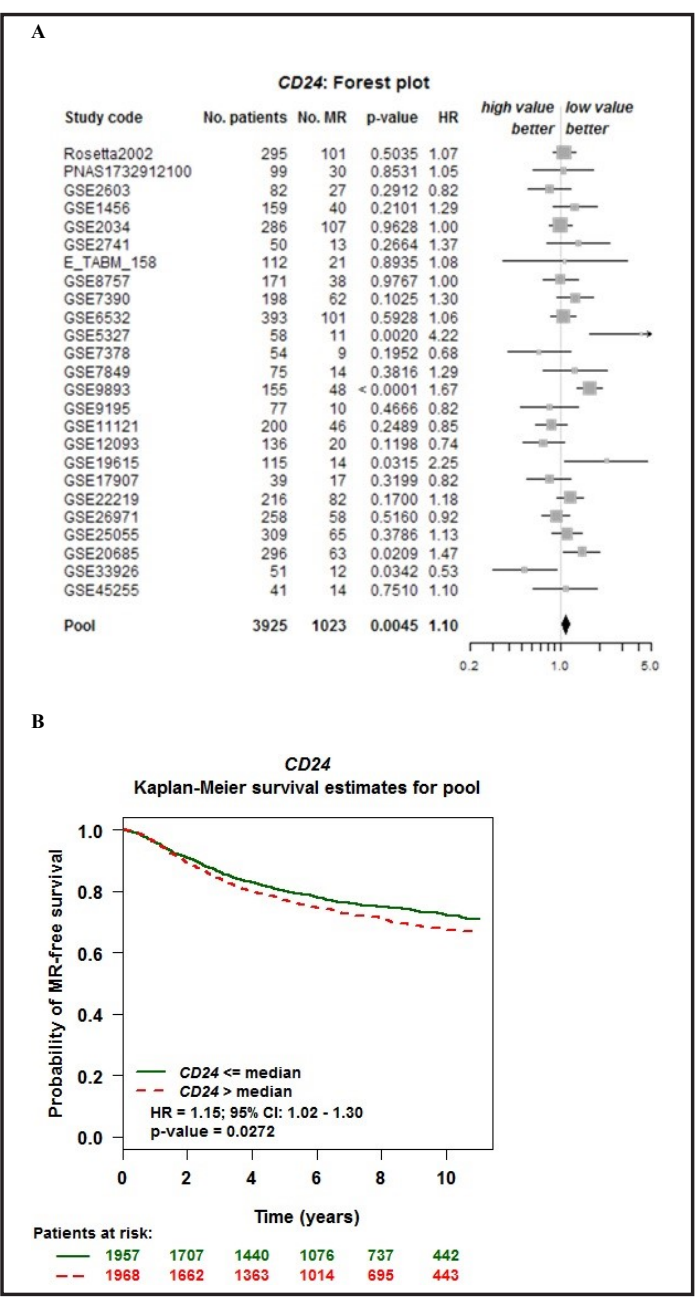

of metastatic relapse (HR $=1.10,95 \%$ CI 1.03-1.18, $p=0.0045$ ) (Fig. 6A). Similarly, high CD24 expression was also associated with worse MRFS (HR =1.15, 95\% CI 1.02-1.30, p =0.0272) (Fig. 6B).

\section{Co-expression of CD24 $\mathrm{mRNA}$}

The co-expression of CD24 was analyzed by Oncomine (Fig. 7A). The co-expression profile of CD24 was identified with a big cluster of 567 genes across 30 breast carcinomas 


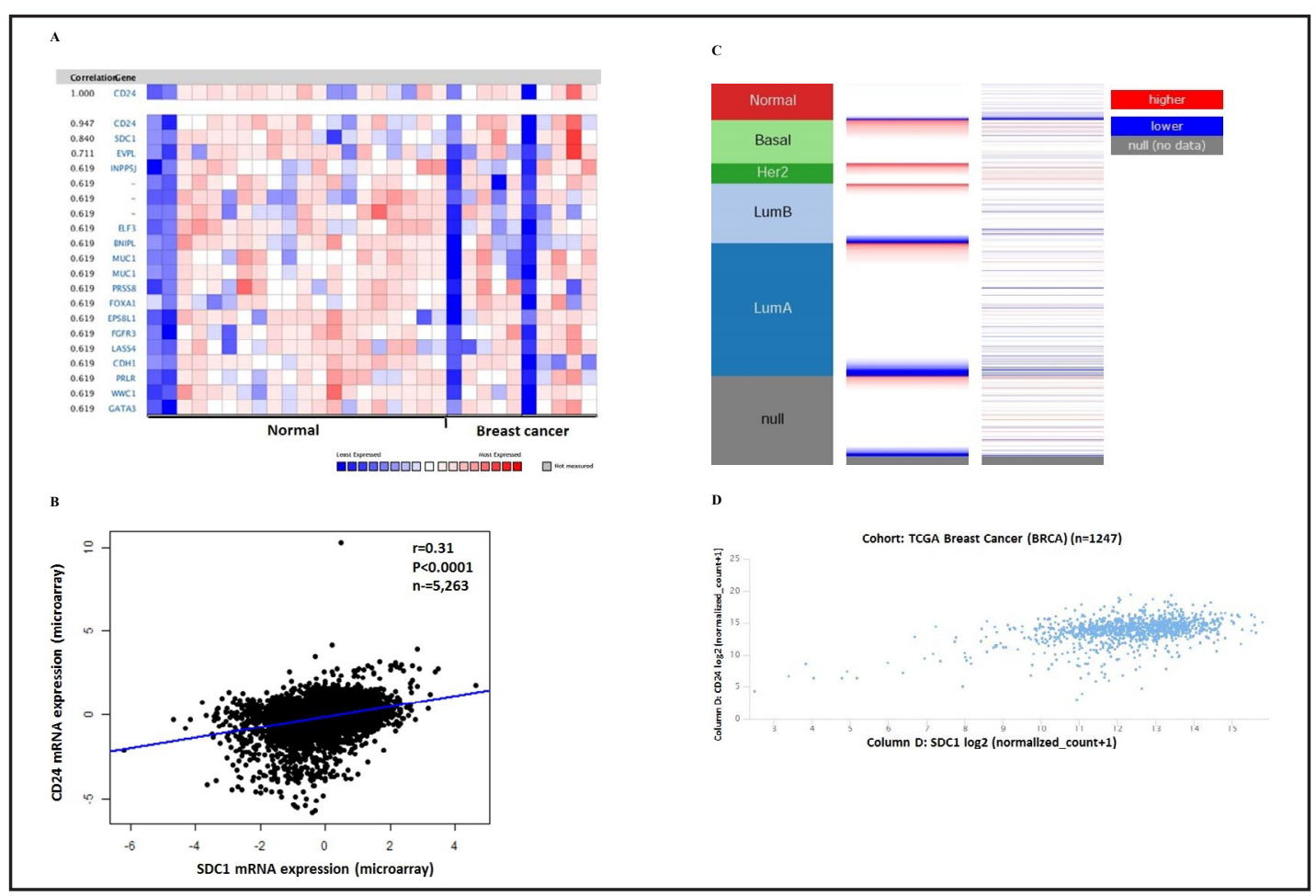

Fig. 7. A: Co-expression genes of CD24 were analyzed by using Oncomine. B: Relationships of CD24 and SDC1 in breast cancer were analyzed by using bc-GenExMiner v4.0; C: The heat map of SDC1 mRNA and CD24 mRNA expression across PAM50 breast cancer subtypes in TCGA database. Data was analyzed using UCSC Xena; D: The correlation between SDC1 and CD24 mRNA expression in TCGA database, Data was analyzed using UCSC Xena.

and 30 normal breast tissues (Fig. 7A) [18]. A highly correlated gene was Syndecan-1 (SDC1), which can enhance multiple oncogene expression in breast cancer [19-22]. Data mining in bc-GenExMiner 4.0 confirmed the positive correlation between CD24 and SDC1 mRNA (Fig. 7B). Analysis of breast cancer patient data in the TCGA database using UCSC Xena (http:// xena.ucsc.edu/) further confirmed this positive correlation (Fig. 7C-D). These findings suggest that CD24 might be closely related to SDC1 signaling pathways in breast cancer.

\section{Discussion}

CD24 is a heavily glycosylated mucin-like membrane protein that acts as a ligand for P-selectin, which is usually defined as a cancer stem cell marker in multiple types of solid tumors [23-26]. Previous studies have shown that abnormal overexpression of CD24 is an unfavorable prognostic factor during carcinogenesis in various neoplasms $[10,15,23,27$, 28]. Meanwhile, CD24 can upregulate the activity of STAT3 and the expression of prototype STAT3-regulated genes [29]. Furthermore, CD24 is associated with HER2 expression and HER2-Akt signaling activity, which can confer resistance to HER2-targeting treatments in HER2-positive cancer [30]. However, the prognostic significance of CD24 expression in breast cancer is still unclear.

In the current study, we evaluated databases on gene expression with clearly defined parameters between tumor and normal tissues. Our analysis using the TCGA database revealed that CD24 mRNA expression was higher in breast cancer tissue than in corresponding normal tissue. Furthermore, Oncomine analysis of cancer vs. normal tissue displayed that CD24 mRNA was significantly overexpressed in male breast carcinoma, medullary breast 
carcinoma, invasive ductal breast carcinoma, and invasive breast carcinoma. Meanwhile, high CD24 expression is associated with HER2 positivity, the basal-like subtype of breast cancer, and TNBC. CD24 expression also correlated with increasing histological differentiation as depicted by SBR grade.

We next investigated the association of CD24 expression with prognosis by using the Kaplan-Meier Plotter, PrognoScan, and bc-GenExMiner. The pooled results revealed that high CD24 expression correlated with shorter OS and RFS. In addition, our data mining and meta-analysis suggested that high CD24 expression also correlated with an increased risk of metastatic relapse and significantly shorter MRFS among patients with breast cancer. These findings demonstrate that the expression level of CD24 might be a useful marker of prognosis in breast cancer.

Through co-expression and correlation analysis, we observed that CD24 might be closely related to the SDC1 signaling pathways in breast cancer. In fact, SDC1 can act as a cell surface adhesion molecule required for the maintenance of cell morphology and interaction with the surrounding microenvironment [31, 32]. Deregulation of SDC1 contributes to cancer progression by promoting cell proliferation, metastasis, invasion, and angiogenesis, and is associated with responses to chemotherapy and with prognosis in multiple solid and hematological cancers [33-35]. Ning Yang et al. found that SDC1 is preferentially expressed in breast carcinoma stromal fibroblasts that can promote the assembly of an architecturally abnormal ECM that is permissive of directional migration and invasion of carcinoma cells [36]. These results indicated that CD24 expression might regulate the tumor migration and invasion associated with SDC1 expression. So CD24 and SDC1 may serve as common prognostic indicators for breast cancer.

In summary, overexpression of CD24 was more common in breast cancer than in corresponding normal tissues and was associated with a worse prognosis. Additionally, SDC1 may be used as a prognostic marker in breast cancer together with CD24, large-scale and comprehensive studies are needed to confirm our findings and determine the clinical utility of CD24 in evaluating breast cancer prognosis.

\section{Acknowledgements}

This work was supported by Scientific Research Project of Shanxi Provincial Department of Health (grant no. 201601070).

\section{Disclosure Statement}

The authors declare to have no competing interests.

\section{References}

1 Zhang L, Yan DL, Yang F, Wang DD, Chen X, Wu JZ, Tang JH, Xia WJ: DNA methylation mediated silencing of microRNA-874 is a promising diagnosis and prognostic marker in breast cancer. Oncotarget 2017;8:4549645505.

- Hong D, Bi L, Zhou J, Tong Y, Zhao Q Chen J, Lu X: Incidence of menopausal symptoms in postmenopausal breast cancer patients treated with aromatase inhibitors. Oncotarget 2017;8:40558-40567.

3 Kwon MJ, Han J, Seo JH, Song K, Jeong HM, Choi JS, Kim YJ, Lee SH, Choi YL, Shin YK: CD24 Overexpression Is Associated with Poor Prognosis in Luminal A and Triple-Negative Breast Cancer. PLoS One 2015;10:e0139112.

4 Lai YH, Chen J, Wang XP, Wu YQ Peng HT, Lin XH, Wang WJ: Collagen triple helix repeat containing-1 negatively regulated by microRNA-30c promotes cell proliferation and metastasis and indicates poor prognosis in breast cancer. J Exp Clin Cancer Res 2017;36:92. 


\section{Cellular Physiology Cell Physiol Biochem 2018;48:111-119 \begin{tabular}{l|l} 
DOI: 10.1159/000491667 & O 2018 The Author(s). Published by S. Karger AG, Basel \\
www.karger.com/cpb
\end{tabular}}

Jing et al.: CD24 is a Potential Biomarker in Human Breast Carcinoma

5 Cui X, Jing X, Long C, Yi Q, Tian J, Zhu J: Accuracy of the urine UCA1 for diagnosis of bladder cancer: a metaanalysis. Oncotarget 2017;8:35222-35233.

6 Cui X, Jing X, Long C, Tian J, Zhu J: Long noncoding RNA MEG3, a potential novel biomarker to predict the clinical outcome of cancer patients: a meta-analysis. Oncotarget 2017;8:19049-19056.

-7 Deng X, Apple S, Zhao H, Song J, Lee M, Luo W, Wu X, Chung D, Pietras RJ, Chang HR: CD24 Expression and differential resistance to chemotherapy in triple-negative breast cancer. Oncotarget 2017;8:38294-38308.

-8 Nakamura K, Terai Y, Tanabe A, Ono YJ, Hayashi M, Maeda K, Fujiwara S, Ashihara K, Nakamura M, Tanaka Y, Tanaka T, Tsunetoh S, Sasaki H, Ohmichi M: CD24 expression is a marker for predicting clinical outcome and regulates the epithelial-mesenchymal transition in ovarian cancer via both the Akt and ERK pathways. Oncol Rep 2017;37:3189-3200.

-9 Overdevest JB, Thomas S, Kristiansen G, Hansel DE, Smith SC, Theodorescu D: CD24 offers a therapeutic target for control of bladder cancer metastasis based on a requirement for lung colonization. Cancer Res 2011;71:3802-3811.

10 Duex JE, Owens C, Chauca-Diaz A, Dancik GM, Vanderlinden LA, Ghosh D, Leivo MZ, Hansel DE, Theodorescu D: Nuclear CD24 drives tumor growth and is predictive of poor patient prognosis. Cancer Res 2017;10.1158/0008-5472.CAN-17-0367

11 Li W, Song D, Li H, Liang L, Zhao N, Liu T: Reduction in Peripheral CD19+CD24hCD27+ B Cell Frequency Predicts Favourable Clinical Course in XELOX-Treated Patients with Advanced Gastric Cancer. Cell Physiol Biochem 2017;41:2045-2052.

12 Yang N, Zhou TC, Lei XX, Wang C, Yan M, Wang ZF, Liu W, Wang J, Ming KH, Wang BC, Xu BL, Liu Q: Inhibition of Sonic Hedgehog Signaling Pathway by Thiazole Antibiotic Thiostrepton Attenuates the CD44+/CD24Stem-Like Population and Sphere-Forming Capacity in Triple-Negative Breast Cancer. Cell Physiol Biochem 2016;38:1157-1170.

13 Bretz N, Noske A, Keller S, Erbe-Hofmann N, Schlange T, Salnikov AV, Moldenhauer G, Kristiansen G, Altevogt P: CD24 promotes tumor cell invasion by suppressing tissue factor pathway inhibitor-2 (TFPI-2) in a c-Src-dependent fashion. Clin Exp Metastasis 2012;29:27-38.

14 Lubeseder-Martellato C, Hidalgo-Sastre A, Hartmann C, Alexandrow K, Kamyabi-Moghaddam Z, Sipos B, Wirth M, Neff F, Reichert M, Heid I, Schneider G, Braren R, Schmid RM, Siveke JT: Membranous CD24 drives the epithelial phenotype of pancreatic cancer. Oncotarget 2016;7:49156-49168.

15 Sagiv E, Starr A, Rozovski U, Khosravi R, Altevogt P, Wang T, Arber N: Targeting CD24 for treatment of colorectal and pancreatic cancer by monoclonal antibodies or small interfering RNA. Cancer Res 2008;68:2803-2812.

16 Schabath H, Runz S, Joumaa S, Altevogt P: CD24 affects CXCR4 function in pre-B lymphocytes and breast carcinoma cells. J Cell Sci 2006;119:314-325.

-17 Sheridan C, Kishimoto H, Fuchs RK, Mehrotra S, Bhat-Nakshatri P, Turner CH, Goulet R, Jr., Badve S, Nakshatri H: CD44+/CD24- breast cancer cells exhibit enhanced invasive properties: an early step necessary for metastasis. Breast Cancer Res 2006;8:R59.

18 Turashvili G, Bouchal J, Baumforth K, Wei W, Dziechciarkova M, Ehrmann J, Klein J, Fridman E, Skarda J, Srovnal J, Hajduch M, Murray P, Kolar Z: Novel markers for differentiation of lobular and ductal invasive breast carcinomas by laser microdissection and microarray analysis. BMC Cancer 2007;7:55.

19 Lim GH, Tan PH, Jara-Lazaro AR, Thike AA, Sim WC, Yap VB, Yip GW: Syndecan-1 is a potential biomarker for triple-positive breast carcinomas in Asian women with correlation to survival. Singapore Med J 2014;55:468-472.

20 Hassan H, Greve B, Pavao MS, Kiesel L, Ibrahim SA, Gotte M: Syndecan-1 modulates beta-integrindependent and interleukin-6-dependent functions in breast cancer cell adhesion, migration, and resistance to irradiation. FEBS J 2013;280:2216-2227.

-21 Ibrahim SA, Yip GW, Stock C, Pan JW, Neubauer C, Poeter M, Pupjalis D, Koo CY, Kelsch R, Schule R, Rescher U, Kiesel L, Gotte M: Targeting of syndecan-1 by microRNA miR-10b promotes breast cancer cell motility and invasiveness via a Rho-GTPase- and E-cadherin-dependent mechanism. Int J Cancer 2012;131:E884896.

-22 Oh JH, Kim JH, Ahn HJ, Yoon JH, Yoo SC, Choi DS, Lee IS, Ryu HS, Min CK: Syndecan-1 enhances the endometrial cancer invasion by modulating matrix metalloproteinase- 9 expression through nuclear factor kappaB. Gynecol Oncol 2009;114:509-515. 


\section{Cellular Physiology Cell Physiol Biochem 2018;48:111-119 \begin{tabular}{l|l} 
DOI: 10.1159/000491667 & $\begin{array}{l}\text { O } 2018 \text { The Author(s). Published by S. Karger AG, Basel } \\
\text { www.karger.com/cpb }\end{array}$
\end{tabular}

23 Kim SK, Park JA, Zhang D, Cho SH, Yi H, Cho SM, Chang BJ, Kim JS, Shim JH, Abd El-Aty AM, Shin HC: Sustainability of CD24 expression, cell proliferation and migration, cisplatin-resistance, and caspase-3 expression during mesenchymal-epithelial transition induced by the removal of TGF-beta1 in A549 lung cancer cells. Oncol Lett 2017;14:2410-2416.

24 Han SA, Jang JH, Won KY, Lim SJ, Song JY: Prognostic value of putative cancer stem cell markers (CD24, CD44, CD133, and ALDH1) in human papillary thyroid carcinoma. Pathol Res Pract 2017;213:956-963.

-25 Durko L, Wlodarski W, Stasikowska-Kanicka O, Wagrowska-Danilewicz M, Danilewicz M, Hogendorf P, Strzelczyk J, Malecka-Panas E: Expression and Clinical Significance of Cancer Stem Cell Markers CD24, CD44, and CD133 in Pancreatic Ductal Adenocarcinoma and Chronic Pancreatitis. Dis Markers 2017;2017:3276806.

-26 Shen YA, Wang CY, Chuang HY, Hwang JJ, Chi WH, Shu CH, Ho CY, Li WY, Chen YJ: CD44 and CD24 coordinate the reprogramming of nasopharyngeal carcinoma cells towards a cancer stem cell phenotype through STAT3 activation. Oncotarget 2016;7:58351-58366.

27 Eyvazi S, Kazemi B, Dastmalchi S, Bandehpour M: Involvement of CD24 in Multiple Cancer Related Pathways Makes It an Interesting New Target for Cancer Therapy. Curr Cancer Drug Targets 2017;10.2174/ 1570163814666170818125036

28 Jimenez P, Chueca E, Arruebo M, Strunk M, Solanas E, Serrano T, Garcia-Gonzalez MA, Lanas A: CD24 Expression Is Increased in 5-Fluorouracil-Treated Esophageal Adenocarcinoma Cells. Front Pharmacol 2017;8:321.

29 Bretz NP, Salnikov AV, Perne C, Keller S, Wang X, Mierke CT, Fogel M, Erbe-Hofmann N, Schlange T, Moldenhauer G, Altevogt P: CD24 controls Src/STAT3 activity in human tumors. Cell Mol Life Sci 2012;69:3863-3879.

-30 Hosonaga M, Arima Y, Sugihara E, Kohno N, Saya H: Expression of CD24 is associated with HER2 expression and supports HER2-Akt signaling in HER2-positive breast cancer cells. Cancer Sci 2014;105:779-787.

-31 Shi S, Zhong D, Xiao Y, Wang B, Wang W, Zhang F, Huang H: Syndecan-1 knockdown inhibits glioma cell proliferation and invasion by deregulating a c-src/FAK-associated signaling pathway. Oncotarget 2017;8:40922-40934.

32 Beauvais DM, Jung O, Yang Y, Sanderson RD, Rapraeger AC: Syndecan-1 (CD138) Suppresses Apoptosis in Multiple Myeloma by Activating IGF1 Receptor: Prevention by SynstatinIGF1R Inhibits Tumor Growth. Cancer Res 2016;76:4981-4993.

33 Mitselou A, Galani V, Skoufi U, Arvanitis DL, Lampri E, Ioachim E: Syndecan-1, Epithelial-Mesenchymal Transition Markers (E-cadherin/beta-catenin) and Neoangiogenesis-related Proteins (PCAM-1 and Endoglin) in Colorectal Cancer. Anticancer Res 2016;36:2271-2280.

-34 Szarvas T, Reis H, Vom Dorp F, Tschirdewahn S, Niedworok C, Nyirady P, Schmid KW, Rubben H, Kovalszky I: Soluble syndecan-1 (SDC1) serum level as an independent pre-operative predictor of cancer-specific survival in prostate cancer. Prostate 2016;76:977-985.

35 Kim SY, Choi EJ, Yun JA, Jung ES, Oh ST, Kim JG, Kang WK, Lee SH: Syndecan-1 expression is associated with tumor size and EGFR expression in colorectal carcinoma: a clinicopathological study of 230 cases. Int J Med Sci 2015;12:92-99.

-36 Yang N, Mosher R, Seo S, Beebe D, Friedl A: Syndecan-1 in breast cancer stroma fibroblasts regulates extracellular matrix fiber organization and carcinoma cell motility. Am J Pathol 2011;178:325-335.

-37 Xia P, Xu XY: Prognostic significance of CD44 in human colon cancer and gastric cancer: Evidence from bioinformatic analyses. Oncotarget 2016;7:45538-45546.

-38 Boon K, Osorio EC, Greenhut SF, Schaefer CF, Shoemaker J, Polyak K, Morin PJ, Buetow KH, Strausberg RL, De Souza SJ, Riggins GJ: An anatomy of normal and malignant gene expression. Proc Natl Acad Sci U S A 2002;99:11287-11292.

39 Silva AP, De Souza JE, Galante PA, Riggins GJ, De Souza SJ, Camargo AA: The impact of SNPs on the interpretation of SAGE and MPSS experimental data. Nucleic Acids Res 2004;32:6104-6110.

40 Jezequel P, Campone M, Gouraud W, Guerin-Charbonnel C, Leux C, Ricolleau G, Campion L: bc-GenExMiner: an easy-to-use online platform for gene prognostic analyses in breast cancer. Breast Cancer Res Treat 2012;131:765-775.

41 Jezequel P, Frenel JS, Campion L, Guerin-Charbonnel C, Gouraud W, Ricolleau G, Campone M: bcGenExMiner 3.0: new mining module computes breast cancer gene expression correlation analyses. Database (Oxford) 2013;2013:bas060. 